\title{
Borderline Ovarian Mucinous Tumor, Endocervical-Like
}

National Cancer Institute

\section{Source}

National Cancer Institute. Borderline Ovarian Mucinous Tumor, Endocervical-Like. NCI

Thesaurus. Code C40038.

A neoplasm of low malignant potential arising from the ovary. It is characterized by the proliferation of neoplastic epithelial cells that resemble endocervical epithelial cells. There is no evidence of stromal invasion. 